\begin{tabular}{|l|l|l||}
\hline \multicolumn{2}{|c|}{ PublisherInfo } \\
\hline \hline PublisherName & $:$ & BioMed Central \\
\hline \hline PublisherLocation & $:$ & London \\
\hline \hline PublisherImprintName & $:$ & BioMed Central \\
\hline \hline
\end{tabular}

\title{
A possible mechanism for immunosuppresion in sepsis
}

\begin{tabular}{|l|l|l||}
\hline \multicolumn{2}{|c||}{ ArticleInfo } \\
\hline \hline ArticleID & $:$ & 4087 \\
\hline \hline ArticleDOI & $:$ & $10.1186 /$ ccf-1999-1342 \\
\hline \hline ArticleCitationID & $:$ & 1342 \\
\hline \hline ArticleSequenceNumber & $:$ & 24 \\
\hline \hline ArticleCategory & $:$ & Paper Report \\
\hline \hline ArticleFirstPage & $:$ & 1 \\
\hline \hline ArticleLastPage & $:$ & 4 \\
\hline \hline & & RegistrationDate : 1999-8-17 \\
\hline ArticleHistory & $:$ & OnlineDate \\
\hline \hline ArticleCopyright & $:$ & Current Science Ltd1999-8-17 \\
\hline \hline ArticleGrants & $:$ & \\
\hline \hline ArticleContext & $:$ & 130541111 \\
\hline \hline
\end{tabular}




\section{Keywords}

Bone marrow cell function, inflammatory mediators, peritonitis, sepsis

\section{Comments}

This study used a recently developed animal model for abdominal peritonitis that appears to be dependent on interferon-gamma, rather than the commonly used model which is dependent on tumor necrosis factor. The effect of abdominal peritonitis on different cell lines is interesting as it may provide an explanation for the immunosuppression (relative to the normal population) often seen in sepsis in the intensive therapy units. Furthermore the study suggests that inflammatory mediators exert an influence on the dysregulation of BM cell function during abdominal sepsis. Obviously this study opens further areas for study of the processes involved in sepsis.

\section{Introduction}

Bone marrow (BM) cell function is controlled by cytokines, including interleukin 3 (IL-3), interleukin 5 (IL-5) and other growth factors that influence cell differentiation. At times of sepsis and septic shock, there is an increased demand for immunocompetent cells. One early reaction is the proliferation of B cell clones in response to cognate antigen. There is also mobilization of polymorphonuclear neutrophils from the BM, early in the septic process. In this septic state, cells are consumed by phagocytosis and antigen - antibody interactions. This response to sepsis results in the appearance of immature band neutrophils in peripheral blood samples.

This study uses a new model of abdominal sepsis involving a mouse with colon ascendensstent peritonitis (CASP). In this recently established model abdominal sepsis is induced by the insertion of a stent in the ascending colon. The survival of the mice, in this model, has been shown to depend on interferon-gamma, rather than on tumor necrosis factor, which is important in the cecal ligation and puncture model of peritonitis.

\section{Aims}


This study aimed to investigate the effect of peritonitis-induced sepsis on the balance of proliferation, differentiation and apoptosis of BM cells in this CASP model.

\section{Methods}

Female mice aged 8 to 12 weeks were used in this study. The CASP procedure involves laparotomy where the colon ascendens was exteriorized and sutured through the antimesenteric portion of the colon just distal to the ileocecal valve. A prepared venous catheter was used to puncture the colonic wall and fixed in place, acting as a stent. For control, sham surgery was performed as described above; with the difference that the stent was fixed outside the colonic wall, avoiding penetration.

BM cell proliferation was measured using cells flushed from the femurs and tibias of the mice and then stained for immunoglobulin G. Apoptosis was estimated by measuring the fraction of cells with DNA strand breaks following specific staining techniques. The function of stem cells and their potency to proliferate and differentiate was measured by counting the colony-forming units (CFUs) of the various stem cell lineages.

All these cells were obtained from septic and control animals at $3 \mathrm{~h}$ (early reversible phase) or $12 \mathrm{~h}$ (late irreversible phase) after the induction of peritonitis.

\section{Results}

BM cells of normal mice showed a spontaneous proliferation rate of $9.9 \%$. After the induction of peritonitis in the CASP animals this rate was significantly augmented to $20.7 \%$ at $3 \mathrm{~h}$ and $23.2 \%$ at $12 \mathrm{~h}$. These cells retained their responsiveness to granulocyte macrophage colony-stimulating factor (GM$\mathrm{CSF}$ ) but were no longer responsive to granulocyte colony-stimulating factor (G-CSF).

In normal mice there were $2.7 \%$ apoptotic cells. Addition of lipopolysacharide (LPS) and cytokines to further stimulate sepsis in extracted cell lines resulted in a dramatic increase in apoptosis (43.6\%). The animals with experimental peritonitis has an enhanced spontaneous rate of bone marrow apoptosis (which was greater at $12 \mathrm{~h}$ than at $3 \mathrm{~h}$ ). They also had an enhanced cytokine-induced rate of bone marrow apoptosis (which was greater at $3 \mathrm{~h}$ than at $12 \mathrm{~h}$ ).

Stem cell function was assessed by counting the number of CFUs. The phagocyte precursor lineage [colony forming units-granulocyte macrophage(CFU-GM)] was stimulated two to three fold by the experimental CASP peritonitis. In contrast, the more mature stem cells of the red cell lineage [colony forming unit-erythrocyte(CFU-E)] were significantly inhibited during the late but not the early phase of sepsis. 


\section{Discussion}

The rate of cell turnover in this study was severely altered by surgical trauma and abdominal sepsis. In sham surgery there was a balanced response (both spontaneous proliferation and apoptosis were stimulated to a similar extent). This may be the result of non specific effects related to catecholamines, or vasodilators such as nitric oxide. Following CASP peritonitis there was an unbalanced, proapoptotic response in BM.

CASP peritonitis affected the hematopoietic stem cells strongly in the late phase of sepsis (12 h). The study demonstrated a lack of effect of sepsis on early precursor lineages [colony forming unitsgranulocyte erythrocyte macrophage megakaryocyte(CFU-GEMM) and burst forming unit-erythrocyte (BFU-E)]. In the CASP mice, this implies that the elevated rate of BM cell apoptosis during sepsis affects differentiated immunocompetent cells more severely than it does hematopoietic stem cells. The immunosuppression seen during sepsis may, therefore, be the result of this selective suppression of immunocompetent cells.

\section{References}

1. Barthlen W, Zanti N, Pfeffer K, Heidecke C-D, Holzmann B, Stadler J: Impact of experimental peritonitis on bone marrow cell function. Surgery. 1999, 126: 41-47 